\title{
Tras los cambios en la poesía: J. L. Martínez
}

\author{
Following the changes in poetry. J. L. Martínez \\ Emma Villazón Richter \\ Universidad de Santiago de Chile, Departamento de Lengua y Literatura, Estudiante de \\ Magíster en Literatura Latinoamericana, Santiago, Chile. \\ Correo electrónico: emmavillazon@outlook.com
}

\begin{abstract}
Este artículo es un primer acercamiento a Aproximación del Principio de Incertidumbre a un proyecto poético (2010) de Juan Luis Martínez, desde la lectura orientalista que E. Lihn y P. Lastra iniciaron. Desde esta perspectiva, propongo que en la obra hay una recreación de elementos de la escritura y la poesía de la tradición china y de ciertos conceptos del conocimiento chino, que da como resultado una apuesta poética radical y de carácter abierto. Este procedimiento, además de construir una obra poética, le añade una dimensión oracular, pues la obra podría dar a leer la pregunta por el estado actual y las transformaciones que le esperan al arte poético; interpelación que estaría lanzada al lector(a), para que este(a) consulte dicho problema en la obra y lo interprete.
\end{abstract}

Palabras clave: Juan Luis Martínez, escritura china, poesía china, I-Ching, paradoja.

This article is a first approach to Aproximación del Principio de Incertidumbre a un proyecto poético (2010) by Juan Luis Martínez from Orientalist reading that E. Lihn and P. Lastra began. From this perspective, I proposed that this work is a recreation of elements of writing and poetry of Chinese tradition, and of certain fundamental concepts of Chinese knowledge, resulting in a radical and open poetic work. This procedure, in addition to create a poetic work, adds an oracular dimension to the work, because this gives to read the question about the current state and the changes that await the poetic art; interpellation thrown to the reader, for that he or she to consult and interpret the problem in the same work.

Key words: Juan Luis Martínez, Chinese writing, Chinese poetry, I-Ching, paradox.

\section{UNA OBRA CARGADA DE INCÓGNITAS}

Antes de desarrollar la lectura sobre la obra Aproximación del Principio de Incertidumbre a un proyecto poético (2010), se intentará dar cuenta de la aparición de esta publicación, ya que su calidad póstuma la ubica en una situación especial frente a los otros trabajos del autor. 
En 2010, diecisiete años después de la muerte de Martínez, se publica Aproximación del Principio de Incertidumbre a un proyecto poético ${ }^{1}$, editado por Ronald Kay. En la nota editorial Kay indica que el manuscrito consistía en veintiocho fotocopias anilladas, tamaño oficio, y que en cada una de ellas se reproducían "dos pictogramas, uno frente al otro, salvo la última [fotocopia] en que remata la serie con uno solo” (2010: 3). En esta edición Kay deshace la pareja de íconos que había en cada página y deja un ícono por página ${ }^{2}$; ajusta la resolución de los íconos; cambia el tamaño de hoja por uno de mayor extensión al del oficio; usa como título para el libro la definición que Martínez dio de su trabajo a la Fundación Andes (institución que otorgó una beca de creación al escritor a comienzo de los años noventa) y toma para la portada el ícono de un hipercubo, que forma parte del contenido del libro. En este sentido, vale la pena hacer notar que la intervención de Kay como editor de la obra no es menor, sino, al contrario, destacable.

Más allá de las modificaciones emprendidas, la ausencia de título en el manuscrito merece atención porque da pie a la duda sobre la conclusión de la obra: ¿podía la obra estar lista para ser publicada sin un título? O, por otro lado, ¿y si Martínez hubiera planificado que no tuviera título? Aun así, cualquiera que fuera la situación, esta no desmerecería la fortuna de que aparezca esta edición. Son conocidos los casos de obras póstumas inconclusas en la historia de la literatura: F. Kafka, E. Hemingway, H. Balzac y, más cerca del presente, R. Bolaño han dejado obras de ese tipo; no obstante, este es un rasgo que debe señalarse al acercarse a Aproximación...

Otro aspecto de interés en relación a la obra es la reciente publicación de un tercer libro póstumo de Martínez: El poeta anónimo (o el eterno presente de Juan Luis Martínez) (Cosac Naify 2012) publicado en Brasil. Este hecho abre la pregunta en torno a cuál podría ser la obra de la que habló Martínez en sus últimos años de vida, en especial cuando se entrevistó con Félix Guattari en 1991 y le dijo: "Yo he trabajado estos últimos quince años en un libro que es muy extenso [...]. Yo he pretendido que sea un libro intolerable. Así es que, si no me encierran, es una casualidad” (2003: 79). La pregunta por esa obra "intolerable" se convierte en una incógnita si se siguen otros comentarios que Martínez da sobre su proyecto en esa entrevista, pues las dos obras publicadas hace poco están relacionadas con China y coquetean con el carácter interminable.

Un elemento más que añade confusión al tratar de dilucidar la obra "intolerable" y de darle un lugar a la obra restante, surge cuando se revisa la explicación que da Cristóbal Joannon, editor de Poemas del otro (2003), sobre la proveniencia del libro que edita:

El libro Poemas del otro cuyo título alternativo es ‘El silencio y su trizadura' hasta ahora había permanecido inédito. Es parte de un trabajo mayor titulado El poeta anónimo (o el eterno presente de Juan Luis Martínez) [...] El poeta anónimo está ordenado a partir de

De aquí en adelante abrevio el título así: Aproximación... y uso la edición publicada Editorial Nómade y Galería D21, 2010, impresa.

Sobre esta modificación del original, Scott Weintraub, en su artículo "Juan Luis Martínez y las otredades...", publicado en la revista venezolana Estudios, 18:35 (enero-julio 2010), ofrece un dato interesante en una de sus notas: "Cabe señalar también que, según Eliana Rodríguez [viuda de Martínez], volverá a aparecer Aproximación del Principio de Incertidumbre [...] en otro momento (bajo el sello de Ediciones Archivo), ya que el texto original de Juan Luis incluía dos imágenes en cada lámina, a diferencia de la versión editada por Kay (entrevista personal con Eliana Rodríguez, 4 de septiembre, 2010)” (162). 
los ocho trigramas del I-Ching: ocho capítulos divididos en tres partes cada uno. Poemas del otro conforma la segunda parte del quinto capítulo ("Notas" en Martínez 2003: 109).

Si en el manuscrito de esta última obra póstuma, Poemas del otro era parte de un capítulo $^{3}$, no resulta desatinado preguntarse si Aproximación... en algún momento no conformó otro capítulo de El poeta anónimo..., que luego fue descartado por el autor, dada la afinidad ya indicada entre las obras. Pero también es verosímil suponer que Aproximación... se haya elaborado de forma simultánea a El poeta anónimo... y que constituya una obra independiente.

Esta última posición es la que maneja Pedro Montes Lira, curador de Galería D21, quien estuvo de cerca en el proceso de publicación de ambas obras póstumas y quien, además, aporta un nuevo dato sobre Aproximación... Según Montes, esta obra es un trabajo autónomo, no una parte de otro; con mayor precisión, en un proyecto visual que Martínez tenía pensado exponer en láminas de gran extensión ${ }^{4}$. Dicha información es interesante porque abre la lectura de la obra a la crítica de arte y no perjudica la posibilidad de leer Aproximación... como una obra poética de carácter visual. Este enfoque se desarrollará en el presente trabajo, en el que, vale subrayar, se considerará solo la obra publicada.

\section{AProXimación... ¿UUN Libro tolerable?}

Es posible que Aproximación..., para algunos lectores, cumpla la pretensión que Martínez anunció que tendría la obra que preparaba cuando conversó con Guattari: resultar intolerable, en el sentido de que exige al lector abandonar la lectura habitual que realiza sobre los libros comunes de poesía. Esto se debe a que la obra es una escritura poética conformada por signos icónicos ${ }^{5}$, que se aparta del poema verbal tradicional. Específicamente, en vez de palabras, el lector se encuentra con imágenes, símbolos y diagramas. Esta condición hace que cualquier lectura sobre la obra tropiece o se frustre si parte en busca de un conflicto o una trama más o menos transparente o ubicable en signos lingüísticos.

En Aproximación... la palabra está reducida a unas cuantas etiquetas que acompañan y complementan la presencia de los signos icónicos. Los íconos son los protagonistas, se hallan en un mayor tamaño que el de las letras y ocupan el centro de

Por lo demás, llama la atención que, al corroborar el dato de Joannon en El poeta anónimo..., Poemas del otro no se encuentre en el libro.

$4 \quad$ Esta información es parte de una entrevista personal realizada a Pedro Montes Lira el 25 de marzo de 2013.

5 El término "icónico" alude de forma general al predominio del carácter visual de los signos que presenta el libro. En un sentido estricto, siguiendo la triada (ícono, índice y símbolo) que propone Charles Sanders Peirce para clasificar al signo, las imágenes de Aproximación... se podrían precisar de la siguiente manera: las unidades violín, araña, calavera, retrato de Rimbaud y traje de astronauta corresponden al ámbito del ícono peirceano, ya que exhiben "la misma cualidad o la misma configuración de cualidades que el objeto denotado" (Todorov y Ducrot 2003: 106), es decir, establecen una relación con su referente a través de la semejanza. Y más precisamente estas se hallan dentro de la "imagen", una de las categorías en que Peirce subclasifica el ícono (imagen, diagrama y metáfora), debido a la relación de estas unidades con el dibujo. Por otro lado, los trigramas del I-Ching, el círculo con cruz y el hipercubo de Warlpiri corresponden al ámbito de los símbolos porque "lo simbolizado" puede existir independientemente del "simbolizante" (124) y existe una fuerza social que les atribuye un sentido. Finalmente, el esquema de neutralidad y el esquema de materia prima pertenecen a la categoría de diagramas, subdivisión que consiste en los signos que "reproducen relaciones entre propiedades". 
cada hoja; podría decirse que son aquello que "llena" la hoja blanca y que se instala como fuente casi muda de sentidos potenciales. Digo "casi muda" porque, debido al rol mínimo que ocupa la palabra, la obra muestra una reticencia extrema hacia lo lingüístico, una casi mudez lingüística, en privilegio de un decir icónico; situación que distingue a esta de La nueva novela de J. L. Martínez ([1977]1985. Santiago: Ediciones Archivo), donde conviven el signo lingüístico, el signo icónico y el objeto, estableciendo relaciones que apuntan a la desestabilización de un sentido único.

Aproximación... está compuesto por cincuenta y cinco íconos de diversa índole. Entre ellos, hay diez íconos substanciales, de carácter simple, que se repiten en todo el libro y generan nuevas unidades dentro de la obra, actuando, de esa manera, como "unidades base". De los diez íconos, siete de ellos son reconocibles fácilmente; se trata de signos icónicos de autoría anónima y uso masivo: un violín, un esquema de materia prima (ilustración de los cuatro elementos básicos de la naturaleza), los ocho trigramas del I-Ching, una araña, una calavera, un retrato de Arthur Rimbaud hecho por P. Verlaine en 1872 y un traje de astronauta. Los tres restantes no corresponden a la iconicidad popular, es decir, no tienen la cualidad convencional de los otros, por lo que a dos de ellos decidí nombrar como "esquema de la neutralidad" y "círculo con cruz"; uno último ya llevaba la etiqueta " $L$ 'hypercube des Warlpiri".

El valor de estas diez unidades base radica en que se combinan entre sí mediante un procedimiento que consiste en que cada unidad base se empareja con cada una de las unidades base restantes, siguiendo un orden específico; o sea, la primera unidad se combina con los nueve íconos restantes; la segunda unidad lo hace con las ocho restantes, y así sucesivamente. Esta operatoria implica que el libro se autogenera o produce nuevas unidades a través de sus propios elementos. El orden antes señalado está dado del siguiente modo: la primera unidad que se combina con el resto es el violín, le sigue el esquema de neutralidad, luego el esquema de materia prima, el círculo con cruz, los trigramas del I-Ching, el hipercubo de los Warlpiri, la araña, la calavera, el retrato de Rimbaud y el traje de astronauta. La secuencia tiene solamente una restricción: ninguna combinación se repite.

Fruto de la operación combinatoria, el libro alcanza el total de cincuenta y cinco íconos; diez de ellos, como señalé, los he denominado unidades base y a los cuarenta y cinco sobrantes, debido al proceso de combinación, he dado en llamarlos "unidades compuestas".

Presento tres unidades de Aproximación... para ilustrar lo descrito.

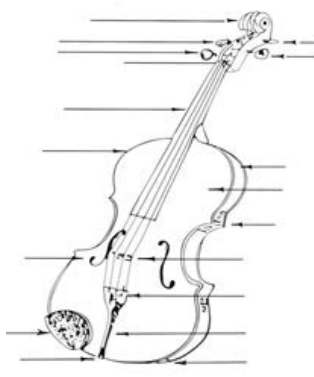

Unidad base "violín"

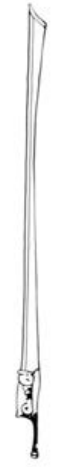

Unidad base "hipercubo de los Warlpiri" 


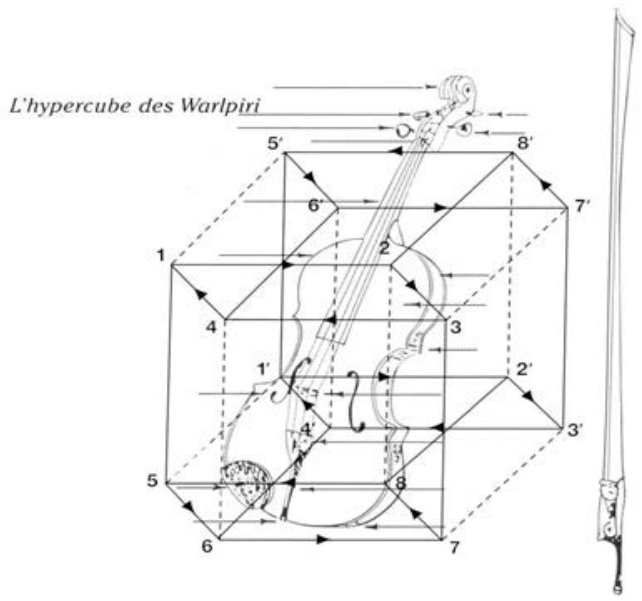

Unidad compuesta "violín-hipercubo de los Warlpiri"

Como se ve, este decir icónico, por sus características, es preciso, económico y puede relacionarse con el lector a través del valor simbólico que transmiten las unidades. De ese modo, la obra resalta porque evade al máximo el discurso y deja la posibilidad del mismo en manos del lector, figura a la que Martínez siempre apeló en sus trabajos, pues para él era "el verdadero y único autor" (2003: 101).

\section{ORIENTE COMO RUTA POSIBLE DE LECTURA}

Desde el año 2010 hasta el presente no existe reseña o estudio alguno publicado sobre Aproximación..., esto lo confirma una búsqueda acuciosa en la red y en la página Web del poeta, que señala: "Es un libro tan complejo que aún nadie se ha tomado el tiempo, ni la molestia, ni por sobre todo la valentía, de hacer una crítica al respecto" (web; Juan Luis Martínez, 21/05/2012). Quizás la carencia de lecturas públicas no hace más que reafirmar la calidad de intolerable que vaticinó su autor, en el hipotético caso de que se refiriera a Aproximación..., la dificultad de manifestar una recepción crítica — que en el espacio académico está obligada a remitirse al discurso— sobre un poemario elaborado primordialmente en base a íconos. Parafraseando a Jacques Roubaud, Aproximación..., afortunadamente, no sería la conocida aspirina literaria de fácil digestión.

La recurrencia que hay en la obra de aspectos anteriormente tratados por Martínez, como la insistencia por la borradura del autor, el juego de ambigüedad entre lo icónico y la palabra y la alusión a las tradiciones poéticas occidental y oriental, considero, permite un acercamiento a través de lo que ya se ha escrito sobre Martínez, especialmente sobre ciertas hipótesis vertidas en torno a La nueva novela. Me refiero particularmente al orientalismo propuesto por Enrique Lihn y Pedro Lastra en "Señales de ruta de Juan Luis Martínez" ([1987] 2001) y luego por Marcela Labraña en "La Nueva Novela de Juan Luis Martínez y la cultura oriental" (1999). Esta perspectiva para acercarse a la obra de Martínez, aunque ha sido poco frecuentada por los críticos, fue considerada por el propio autor como una referencia 
ineludible de aquel trabajo póstumo que emprendía cuando dialogó con Guattari: "Mi próximo trabajo tiene mucho que ver con China; con la China actual, incluso" (2003: 93).

Pero antes de entrar a analizar la obra en cuestión, es necesario recordar un antecedente de la relación que Martínez tenía con la tradición china. Este trabajo está en La nueva novela y lleva justamente el subtítulo "La poesía china" (97). En esta sección aparecen dos poemas chinos traducidos al castellano y un poema chino en escritura ideográfica. El primer poema en castellano es de Shen-hsui y establece, a grandes rasgos, la metáfora del cuerpo con un árbol Bodhi; el segundo, pertenece a Hui-neng y parece ser una respuesta al anterior poema, solo que desde una proposición negativa, pues niega la existencia del árbol Bodhi. Si nos enfrentamos a la lectura de este texto desde la perspectiva china, cada poema se manifiesta como si uno fuera la cara y el otro el reverso de un mismo objeto, ambos tienden a mostrar dos miradas sobre un mismo río: el hombre. Los poemas no remiten a una confrontación, sino al dualismo del Yin y el Yang, que al acoger a dos unidades complementarias afirma la conjunción de ambas, su interacción permanente. Desde esta mirada, no hay contradicción, anulación de premisas o búsqueda de sinsentido, sino una afirmación de la complementariedad que promueve una ambigüedad particular.

Ahora, con respecto a la presencia de lo oriental en la obra de Martínez, Lihn y Lastra indican que "el Norte de Martínez es el Oriente, no solo por las paráfrasis y citas falsas o verdaderas del budismo Zen, sino por la aplicación de lo que Ernest Fenollosa consideraba el método científico de la poesía y del sistema ideográfico de los chinos. Esta última pista, la alusión al sistema ideográfico chino, a pesar de los años que tiene, se hace contundente hoy en Aproximación..., pues la estructura del libro pareciera convocar a que fuera leído desde las coordenadas de un poema chino y la noción del sistema ideográfico oriental. Esto significa leer las imágenes/íconos desde una condición espacio-temporal distinta, como elementos dispuestos de una manera que rompen con la lectura secuencial, rasgo formal que desde comienzos de la década del 50 los poetas concretos aplicaban en sus creaciones. En este sentido, los concretos y Martínez están emparentados porque coinciden en recuperar la noción de ideograma que revisa y recrea, en primera instancia, Ezra Pound. Escuchemos lo que dicen los brasileros en un manifiesto sobre esto:

(...) de ahí la importancia de la idea de ideograma, desde su sentido general de sintaxis espacial o visual, hasta su sentido específico (fenollosa/pound) del método de componer basado en la yuxtaposición directa —analógica, no lógico-discursiva — de elementos (De Campos, de Campos y Pignatari 1999: 85).

Siguiendo esta línea, es verosímil plantear que Martínez en Aproximación... se apropia de elementos de la escritura china, pues usa signos no verbales que ubica en el centro de la página, lo que implica la producción de una escritura no lineal que ofrece una espacialidad y una temporalidad distintas, ya no determinadas por la silueta de la línea por línea que caracteriza al discurso, sino por el orden de aparición de los signos. Esta situación lleva a la hipótesis de que Martínez manipula los signos icónicos de esta obra póstuma como si fueran ideogramas, ya que cada unidad icónica del libro es autónoma, sobresale por su aspecto visual y cobra valor según el orden de aparición en el espacio gráfico, y según cómo se combine con otras unidades. 
Labraña reconoce este rasgo de la escritura china cuando, en su artículo sobre La nueva novela, señala la diferencia entre la poesía china y la poesía occidental: "La poesía, en general, debido a su naturaleza lingüística, se desarrolla en el tiempo, se expresa sucesivamente. La poesía china, en cambio, dispone palabras en el espacio" (1999: 53).

Al respecto, es oportuno citar nuevamente a los concretos por la afinidad que tienen con Martínez en cuanto a la valorización del ideograma: "ideograma: apelación a la comunicación no-verbal. el poema concreto comunica su propia estructura: estructura-contenido. el poema concreto es un objeto en y por sí mismo” (De Campos, de Campos y Pignatari 1999: 86). En los concretos, el aprovechamiento del espacio gráfico y la consideración de la palabra como signo, además de significativo, también gráfico y fonético, se observa en el famoso poema "Beba coca-cola" de Décio Pignatari.

También resulta pertinente mostrar cómo el método de composición de nuevos caracteres basado en la yuxtaposición se produce en la escritura china. Sirva de ejemplo para ello esta selección de ideogramas que usa el reconocido orientalista Françoise Cheng en La escritura poética china..., con el objeto de ilustrar cómo los signos se combinan entre sí:

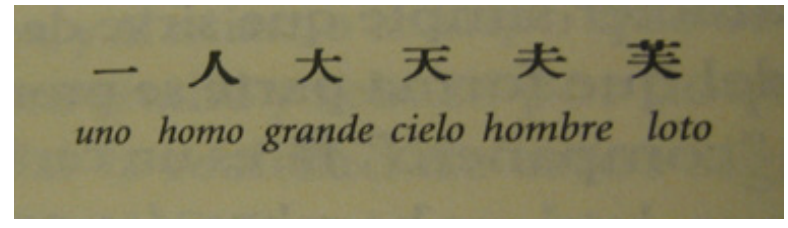

Siguiendo la explicación de Cheng, la combinación de "uno" con "homo" forma el carácter "grande". Se obtiene "cielo" agregando el trazo de "uno" por encima de "grande". El ideograma "hombre" surge cuando se sobrepasa un trazo del carácter "cielo". El carácter "loto" se forma a través de la combinación del signo "hombre" con el radical "hierba" (Cf. Cheng 2007: 14).

Considerando esta capacidad productiva de la lengua china que permite numerosas conjunciones, vale la pena mencionar el temor que Martínez le manifestó a Guattari cuando le hablaba de la obra que preparaba: "Yo estoy en un trabajo que le explico, no sé si terminándolo, porque se ha producido el encuentro con una obra que podría ser interminable, lo cual es de mucho riesgo [...] Son pedacitos que incluso se conectan. Es un trabajo de Penélope” (Martínez 2003: 82). Por ello, es coherente postular que Aproximación... toma el método de yuxtaposición de la escritura china y mediante este rasgo crea un mecanismo de combinación que es posible de ser continuado, porque la obra aplica una yuxtaposición de íconos pares, pero bien se podría seguir el tejido de la trama introduciendo una yuxtaposición de tres unidades... o de más..., e incorporar nuevas unidades base.

Una segunda asociación posible con respecto al procedimiento de yuxtaposición de los íconos se puede hacer estableciendo una correspondencia entre este método y el de la formación de los hexagramas del I-Ching. Los sesenta y cuatro 
hexagramas o posibles respuestas del oráculo, son el resultado de la combinación de ocho unidades mínimas llamadas trigramas. Estas se combinan entre sí mediante la fusión entre pares, es decir, entre dos trigramas; su unión da las seis líneas de un hexagrama. Solo habría una mínima diferente entre ambas combinaciones: la combinación de trigramas se diferencia de la que se produce en Aproximación... porque un trigrama se puede combinar consigo mismo, situación que no se da en Aproximación...

Un segundo rasgo oriental latente en la obra está relacionado con la poesía china y es reconocible en la elección de signos icónicos para crear un libro de poesía; este rasgo, vale decir, fue mencionado ya por Labraña en la preferencia de Martínez por lo icónico (Cf. 1999: 53). En la cultura oriental la relación que existe entre la escritura de los caracteres chinos y el dibujo es histórica, pues desde la antigüedad la caligrafía se inclinaba hacia una representación gráfica de los hombres y la naturaleza. Como una derivación de este vínculo, en la estética china también es antigua la relación entre poesía y pintura.

Para desarrollar la explicación de este rasgo, es necesario señalar lo que François Cheng comenta sobre la pintura en China: "En la tradición china la pintura se llama wu-sheng-shi, 'poesía silenciosa', y ambas artes pertenecen a un mismo orden. Muchos poetas se dedicaban a pintar, pero todo pintor se debía a la poesía” (2007: 24). Esto significa que en la China antigua ambas prácticas no poseían lindes definidos entre una y otra, porque no estaban divididas de la manera en que lo están en Occidente; existía la figura del "poeta-pintor" (ibíd.) como un ideal a seguir entre los poetas y los pintores. Y lo que es aún más interesante: la categoría "poesía" no remitía únicamente a la escritura de un texto, sino, además, a la creación pictórica.

Cheng comprende el vínculo de ambas prácticas del siguiente modo: "Lo que une en primer lugar a la poesía y la pintura es precisamente la caligrafía. Y la manifestación más significativa de esta relación ternaria — que constituye la base de un arte completo - es la tradición que consiste en caligrafiar un poema en el espacio en blanco de una pintura” (ibíd.).

Parafraseando a Cheng, el elemento de enlace, en el fondo, es el arte del trazo. Para escribir se debe conocer la caligrafía de los ideogramas, los que evocan a una antigua y ya difusa representación gráfica del hombre y de las cosas. Se aprende a escribir en parte dibujando. Es de suponer que para un artista como Martínez involucrado en el arte contemporáneo como en la poesía, la concepción de que no hubiera división precisa entre dichas prácticas lo sedujo sobremanera.

Pero el vínculo entre poesía y pintura china no solo se da por una cuestión técnica, sino porque la búsqueda de estas actividades (así como ocurre con la música y los mitos) está al servicio de los objetivos estéticos chinos, que están íntimamente ligados con el pensamiento chino. Estos consistirían, según Cheng, en "una simbolización sistemática de los elementos de la naturaleza y del mundo humano; constitución de las figuras simbólicas en unidades significantes, estructuración de estas unidades según ciertas leyes fundamentales ajenas a la lógica lineal, generación de un movimiento semiótico regido por un movimiento circular en el cual todos los componentes se implican...” (2007: 33 y 34). Nótese cómo estos objetivos coinciden plenamente con ciertas características ya descritas de la obra de Martínez.

Ahora bien, desde esta perspectiva, ¿cómo nombrar a las unidades de Aproximación...? ¿se trata de ideogramas, pictogramas, poemas, dibujos?... Quizás 
la cita que señala Cheng de Su Dong-po, un antiguo poeta chino, cuando se refería a las obras de un colega suyo, Wan Wei, pueda dar más pistas: “...pudo decir de él 'que sus pinturas son poemas, y sus poemas pinturas”” (24). Por lo tanto, si hubiera que nombrar de alguna manera a las unidades icónicas, debería primar en esa denominación la noción china del vínculo entre pintura y poesía y así también subrayar la capacidad combinatoria, mediante la yuxtaposición, que presentan los signos de Martínez al igual que los ideogramas; este rasgo, vale decir, no lo poseen los pictogramas ${ }^{6}$. En este sentido, es adecuado describir a los signos de Aproximación... como poemas-icónicos o poemas visuales que, en su combinación, actúan como ideogramas.

Si se asume esta posición, el libro no solo tendrá cincuenta y cinco poemas visuales, sino también todos ellos pueden constituir un largo poema visual, posible de leer en su conjunto debido a la conexión que presentan entre sí.

Por otro lado, es necesario reconocer que las unidades icónicas que nos interesan tienen una gran diferencia con la estética china, pues Martínez toma íconos conocidos (un violín, un esquema de materia prima, una araña, una calavera, los ocho trigramas del I-Ching, un retrato de Arthur Rimbaud de 1872 y un traje de astronauta y un hipercubo con el nombre de "L`hypercube des Warlpiri"7) e inventa nuevos íconos (un esquema de la neutralidad y un círculo con cruz). Por lo tanto, reutiliza íconos conocidos, de autoría anónima debido a su uso popular y los reúne con íconos creados por él. Se podría decir entonces que el arte del trazo en Aproximación... desaparece para dar cabida a la reutilización de elementos de segunda mano y a la combinación de los mismos con otros nuevos, a fin de obtener una nueva obra. Esta característica del uso de materiales de procedencias heterogéneas marca el gesto de vanguardia artística ya identificado en las anteriores obras de Martínez y remarca el lazo entre elementos del mundo oriental y occidental que presenta esta obra. Si bien este aspecto no será tratado en este trabajo, vale señalar que la práctica del montaje, común entre los vanguardistas, ayuda a intensificar en Aproximación... el efecto de fragmentación y desconcierto, pues la obra no refiere a una realidad identificable, sino que alude a un universo extraño; situación que le da el carácter de obra abierta y exige del lector un rol tremendamente activo.

En consecuencia, recapitulando la relación con la tradición china, dos podrían ser los rasgos formales de escritura china que recoge Martínez para su (re)creación. Uno, la disposición de las unidades icónicas, que juegan a ser caracteres ideográficos, pues, además de unidades base, existen unidades compuestas y todas las unidades se presentan en un orden específico (una sintaxis), lo que evoca el carácter aislante y analítico de la lengua china. Y dos, el vínculo ya expresado entre poesía y pintura.

Justamente la diferencia entre pictograma y signo es que el primero no constituye un sistema, mientras que el signo es la unidad mínima de un código. Todorov y Ducrot marcan la diferencia de este modo: "Los pictogramas forman series abiertas y no organizadas, mientras que el lenguaje puede concebirse como una combinatoria: un número reducido de sonidos produce un número muy elevado de palabras; éstas, a su vez, producen un número infinito de frases" (2003:229).

L `hypercube des Warlpiri es una figura teórica propuesta por la antropóloga Barbara Glowczewski a través de la cual pretende explicar la organización ritual y la clasificación parental del pueblo Warlpiri de Australia. Cf. Casajus, Dominique. "L-Hypercube est-il bon à penser?". Persee 130: 111-118 


\section{ESBOZO DE UNA POÉTICA DE LA INCERTIDUMBRE}

Con el fin de hilvanar una posible lectura, vuelvo a la descripción de la estructura de Aproximación... El libro, como mencioné, está conformado por diez íconos o unidades base que se multiplican según una combinatoria de yuxtaposición. Las diez unidades se relacionan entre sí, partiendo de una combinatoria que consiste en que cada unidad base se combina con las unidades base restantes y produce una serie de unidades compuestas.

No obstante, en este mecanismo aparentemente predecible hay una desviación a la norma que impone la combinatoria. Las diez unidades base tienen un orden de aparición ya señalado: 1. Violín, 2. Esquema de neutralidad, 3. Esquema de materia prima, 4. Círculo con cruz, 5. Trigramas del I-Ching, 6. Hipercubo de los Warlpiri, 7. Araña, 8. Calavera, 9. Retrato de Rimbaud y 10. Traje de astronauta. Todas las unidades base respetan esta secuencia, salvo la unidad base círculo con cruz; cuando a esta le corresponde combinarse con araña lo hace con calavera. Este movimiento rompe con aquella supuesta combinatoria precisa o "coherencia interna del juego iconográfico”, que señala Kay en la nota editorial (Kay 2010: 3). Justamente el juego de Martínez se revela como uno aparentemente matemático, pero impredecible.

Ante esta breve descripción formal de Aproximación..., surgen las preguntas:

a. ¿Cómo leer la selección y el orden de aparición de esas diez unidades base? ¿habría un relato en esa secuencia?

b. ¿Cómo leer la operación de yuxtaponer una unidad sobre otra?

c. ¿Cómo leer la interrupción en el orden de combinación de la serie de la unidad base círculo con cruz?

d. ¿Cómo leer la recurrencia de la figura subyacente del octaedro en las unidades esquema de la neutralidad, esquema de materia prima, círculo con cruz, hipercubo de Warlpiri, trigramas del I-Ching y la araña?

Trataré de lanzar breves esbozos de hipótesis sobre cada punto.

a. Tanto el inciso a. como el b. pueden constituir dos ejes de lectura: el primer eje, al que se llega de forma inmediata por nuestro hábito de lectura lineal, es el horizontal, es el que corresponde a todas las unidades combinadas entre sí; el segundo eje es el vertical y es el que constituye el orden de aparición de las diez unidades base; este no es visible a primera vista, pero surge una vez que se identifica el mecanismo de combinación.

Esta característica de doble lectura acentúa la relación del libro con China, su presencia casi fantasmal. Cheng habla del rasgo de doble lectura al referirse a la cualidad del poema clásico lüshi, que está compuesto por versos paralelos y no paralelos, que desplazan la lectura acostumbrada (Cf. 42). Por lo demás, si se habla de doble lectura, dicha situación remite a la figura de la dualidad china, que consiste en la interacción entre polos complementarios y que es la piedra angular del pensamiento chino que irradia a sus demás manifestaciones culturales y está simbolizada en el Yin y el Yang.

Lectura del eje vertical: creo que las diez unidades aluden a conceptos que han nutrido a la poesía de la modernidad. En consecuencia, resulta interesante cómo una apresurada traducción personal de los íconos y su valor simbólico puede develar un campo de conceptos: música - ideas del libro - materia prima del libro - Dios - la 
adivinación/Oriente -la ciencia (lo nuevo) y no Occidente (lo antiguo) ${ }^{8}$ - el autor ${ }^{9}-$ muerte - el poeta que inaugura la poesía de la modernidad - el porvenir de la poesía. En esta secuencia se podría hablar de un grupo de conceptos que han acompañado al arte poético. A primera vista no es posible identificar un ordenamiento histórico sobre el recorrido de la poesía en Occidente, sin embargo llama la atención que la primera unidad base inicie con la música, elemento vinculado con la poesía desde sus orígenes y que, después de Rimbaud, la última figura sea la del astronauta, la de aquel que se lanza a recorrer territorios desconocidos. Resulta sugerente que el astronauta aparezca después de Rimbaud, porque si la figura del poeta francés está ligada con la del poeta de la modernidad, la unidad astronauta encierra la incógnita sobre el paso que ha dado la poesía después de Rimbaud y también, obviamente, provoca la pregunta sobre el paso todavía no escrito que este arte dará en el porvenir.

a. Lectura del eje horizontal: como las diez unidades base remiten a un mismo concepto, resultan equivalentes, por ello es posible su interrelación, es decir, que se espejeen o impliquen entre sí. A pesar de que provienen de diferentes territorios (la ciencia, la religión, las artes -la música, la poesía-, la adivinación, Occidente, Oriente) su conexión sugiere que conviven en su diversidad. Al respecto, una de las equivalencias más interesantes es MATERIA PRIMA $=$ NEUTRALIDAD $^{10}$ producida por la unión de la unidad esquema de materia prima y esquema de la neutralidad, porque evidentemente Aproximación..., en su construcción, remarca el ideal de Martínez de alcanzar "la disolución absoluta de la autoría, la anonimia... una obra en la que no [le] pertenezca casi ninguna sola línea” (Martínez 2003: 82) y afianza el tipo de autoría del "bricoleur" o de aquel que suma fragmentos personales y ajenos.

b. La interrupción es relevante porque evidencia nuevamente que más que pretender construir una obra poética cerrada y predecible, Aproximación... propone el asombro, la incertidumbre ante el mecanismo que trama, pues rompe con sus propias reglas de juego.

c. La figura del octaedro, insinuada recurrentemente en varias unidades, remite a los ocho trigramas o unidades mínimas que, como señalé, forman los sesenta y cuatro hexagramas que constituyen los posibles resultados oraculares que ofrece el

8 Propongo esta traducción en base a la siguiente definición de los términos: en geometría se entiende por hipercubo a una figura formada por dos cubos tridimensionales en un cuarto eje dimensional, es decir, a un cubo de cuatro dimensiones. Lo llamativo de esta figura es que nadie puede ver un hipercubo porque estamos sujetos a tres dimensiones, por lo que solo podemos ver la proyección de lo que sería uno. Cf. http://es.wikipedia.org/wiki/ Hipercubo. Warlpiri es el nombre de un grupo indígena del norte de Australia, así como la denominación de su lengua. Cf. http://es.wikipedia.org/wiki/Idioma_Warlpiri. Ambos conceptos pretenderían establecer una alianza entre lo nuevo que produce la ciencia y el conocimiento antiguo, una cultura indígena no occidental.

9 El autor como una araña que queda atrapado en su propio tejido. Merece aquí citar una frase del mismo Martínez: "El autor es una suerte de Penélope que teje el mismo texto con la misma lana", en Poemas del Otro (102). Vale la pena también citar un pasaje de lo que dice Cirlot de la araña en su Diccionario de símbolos: "En la araña coinciden tres sentidos simbólicos distintos, que se superponen, confunden o disciernen (...) son: el de la capacidad creadora de la araña al tejer su tela; el de su agresividad; y el de la propia tela, como red espiral dotada de un centro (...). La araña en su tela es un símbolo del centro del mundo, y en ese sentido es considerada en la India como Maya, la eterna tejedora del velo de las ilusiones” (2007).

10 Para leer la neutralidad en Martínez, además de seguir a M. Foucault en cuanto al concepto función autor, se debe revisar el ensayo de Carla Cordua (2001). 
I-Ching. Valga el siguiente esquema descriptivo de los ocho trigramas del I-Ching ${ }^{11}$, para confirmar el guiño a la tradición oriental que poseen los signos que presentan ocho aristas en Aproximación...

\begin{tabular}{|c|c|c|c|c|c|}
\hline \multicolumn{3}{|c|}{ Nombre } & Cualidad & Imagen & Familia \\
\hline & ch'ien & lo creativo & Fuerte & Cielo & Padre \\
\hline$=\bar{z}$ & Kun & lo receptivo & Abnegado & Tierra & Madre \\
\hline$= \pm$ & Chen & lo suscitativo & Movilizante & Trueno & primer hijo \\
\hline$=$ & Kan & lo abismal & Peligroso & Agua & segundo hijo \\
\hline$=$ & Ken & el aquietamiento & Quieto & Montaña & tercer hijo \\
\hline$\overline{\bar{z}}$ & Sun & lo suave & Penetrante & viento, madera & primera hija \\
\hline$=$ & $\mathrm{Li}$ & lo adherente & Luminoso & Fuego & segunda hija \\
\hline$=-$ & Tui & lo sereno & Regocijante & Lago & tercera hija \\
\hline
\end{tabular}

Cuadro descriptivo de los ocho trigramas del I-Ching

La presencia del libro sagrado chino en Aproximación... es primordial, porque tendría, a mi modo de ver, la funcionalidad de convertir a la obra en un libro de consulta para el lector(a), es decir, Aproximación... podría servir para describir una situación presente e indicarle el modo en que se transformará la misma en el futuro. Esto sería posible si se consideran a las cincuenta y cuatro unidades del libro como resultados posibles de los cambios, es decir, como si fuesen hexagramas que ofrecen distintas respuestas a las preguntas de quien lanza las varillas o las monedas. La interpretación de cada unidad, que jugaría a ser un hexagrama, dependería de la lectura individual que provocan las imágenes.

Las consultas estarían abiertas a cualquier pregunta, aunque la particularidad del I-Ching de Aproximación... es que este sistema adivinatorio pareciera sugerir la consulta por la situación presente y el porvenir de la poesía moderna, por las mutaciones que le esperan, por las señales que hay que seguir ante la "crisis de fin de siglo"12 que Martínez remarcó tanto y que comprendía como una crisis de la palabra, del arte y de Occidente. En este sentido, los íconos que se combinan en la obra cobrarían el valor de conceptos en torno a la poesía que han ido definiendo y permitiendo mutar a lo largo del tiempo y que están ahora a la espera de una nueva instancia.

11 La interpretación de los trigramas del cuadro fue extraída de http://es.wikipedia.org/wiki/I_Ching, consultado el 10/06/12, información que fue corroborada por los esquemas del libro citado de Mirko Lauer (1990: 20-21).

12 La crisis de fin de siglo corresponde al debate que introducen filósofos contemporáneos posestructuralistas, como M. Foucault, cuando, por ejemplo, este señala la muerte del sujeto. Esta crisis que se manifiesta también en el signo lingüístico, en el arte y en Occidente es un problema central que marca la obra Martínez. Valga recordar, para comprender esto, la conocida respuesta que el autor da a M. Esther Roblero: "Soy un poeta apocalíptico. Creo en el fin de una época. Se perdió la imagen sólida del mundo. Los conocimientos acumulados sólo han servido para la confusión. Nuestra confianza en el lenguaje también se ha perdido. ¡Cosa terrible!” (Martínez 2003: 67). 
Debido al carácter complejo del I-Ching, a la dificultad de catalogarlo en un área del conocimiento, la conexión que Aproximación... establece con este libro sobrepasa la dimensión oracular. Como lo señala Salvador Elizondo (1992), el I-Ching, según la exégesis que ha tenido, es también el libro de la sabiduría china, es la fuente desde hace tres mil años de las dos ramas del pensamiento chino: el confucionismo y el taoísmo. Del I-Ching parte el principio dualista del Yin y el Yang, que consiste en que los elementos contrarios no están dispuestos para un enfrentamiento violento, como se piensa en Occidente (Elizondo 1992: 5), sino que ambos son elementos complementarios que dan cuenta de una conjunción dinámica.

En el breve ensayo sobre el I-Ching del escritor mexicano, este desarrolla la noción de la dualidad oriental del siguiente modo: "Si para Occidente el mundo está constituido por una posibilidad de identidad que expresa una relación lógicamente definible, para la filosofía china el mundo está constituido por un número infinito de correlaciones cambiantes que sólo pueden expresarlo en un instante dado” (1992: 6).

La idea de la interacción entre elementos dispares, pero complementarios, sumada a la del cambio permanente, podría servir para comprender el movimiento del que son objeto las unidades en Aproximación..., su constante metamorfosis a través de la operación de la yuxtaposición.

Otro rasgo del I-Ching, apropiado por Martínez, es la tendencia hacia la síntesis. En Aproximación... hay una preferencia por lo icónico sintético antes que por la palabra, porque lo icónico no dirige hacia un discurso lógico-analítico, sino a un texto visual caracterizado por el uso del espacio, del tiempo y de una sintaxis que lleva hacia otro camino de lectura. Vale decir que la síntesis es un rasgo que gobierna en la cultura china. En el I-Ching la primera expresión de síntesis es, citando a Elizondo, "la representación de los elementos correlativos mediante las líneas quebradas o continuas", que componen los trigramas, y que, "en sus orígenes, conformaban la primera afirmación de principios de esta cosmogonía" (11). La síntesis es el procedimiento en que se acerca la cultura china a conocer el mundo, sin embargo — volviendo a citar a Elizondo-, "los elementos que constituyen la síntesis no tienen el carácter de afirmación o de negación que tradicionalmente se atribuiría a los elementos en Occidente, sino que, por el contrario, constituyen una conjunción determinativa del mundo" (1991: 12).

Contrariamente, en Occidente la relación con el mundo se establece, como indica Elizondo, a través del análisis y la elaboración de juicios, procedimiento que pone en conflicto elementos opuestos hasta su resolución (1992: 5).

De este modo, como en la cultura oriental no existen elementos antitéticos, dispuestos para el debate dialéctico, lo que se asume más bien es la síntesis de una naturaleza que fluye permanentemente y de manera provisoria, donde es imposible establecer relaciones causales hacia atrás como para adelante en el tiempo. En esta línea, cabe subrayar que el flujo confuso y dinámico de la naturaleza y del ser humano tendría como condición esencial lo que, en términos de Elizondo, Occidente llama "paradoja o ambigüedad" (17).

Llegados a este punto, Aproximación... podría ser un intento de aprehender el ritmo de las mutaciones de la poesía a través de la síntesis (por ello la elección de las imágenes como unidades centrales) al reunir elementos complementarios (Occidente- 
Oriente; la ciencia en el hipercubo y lo primitivo en la mención a los Warlpiri; Dios-el autor..., por citar algunos), que aluden a ella. Esta unión de elementos complementarios y contradictorios exacerbaría el gesto de la paradoja para eso que llamamos "poesía", pues nos mostraría a esta como un río que ha recibido y recibe miles de gestos y que fluye en esa ambigüedad o incertidumbre.

En este sentido, Aproximación... podría ser una metáfora de ese río siempre cambiante y siempre el mismo que llamamos poesía, y que a la vez lanza la pregunta por los rostros futuros que acogerá.

\section{Agradecimientos}

Mis agradecimientos a Andrés Ajens quien fue un apoyo valioso, a través de conversaciones y sugerencias, en la investigación y escritura de este artículo. También agradezco a Felipe Cussen por haberme alentado en mi aproximación inicial a este trabajo en el seminario "Poéticas y prácticas contemporáneas", que dictó en el Instituto de Estudios Avanzados de la Universidad de Santiago de Chile en el primer semestre del 2012, en el que tuve la oportunidad de participar.

\section{OBRAS CITADAS}

Casajus, Dominique. 1994. "L-Hypercube est-il bon a penser?". Persee 130: 111-118.

Cheng, François. 2007. La escritura poética china. Seguido de una antología de poemas de los Tang. Trad. Juan Luis Delmont, con la colaboración de Eugenio Montejo. Valencia: Pre-Textos.

Cirlot, Juan Eduardo. 1997. Diccionario de símbolos. Madrid: Ediciones Siruela.

Carla Cordua "J.L. Martínez. Bloqueo lírico y desbloqueo" en Fariña, Soledad y Hernández Elvira (comp.). 2001. Merodeos en torno a la obra de Juan Luis Martínez. Santiago: Intemperie Ediciones, 22-26.

De Campos, Haroldo, de Campos, Augusto y Pignatari, Decio. 1999. "Plano piloto de la poesía concreta”. Galaxia concreta. México D.F.: Universidad Iberoamericana, Biblioteca Francisco Xavier Clavijero. 85-87.

Elizondo, Salvador. 1992. "El I-Ching". Teoría del infierno y otros ensayos. México: El Colegio Nacional, Ediciones del Equilibrista.

Kay, Ronald. 2010. "Nota editorial” en Martínez, Juan Luis. Aproximación de un Principio de Incertidumbre a un proyecto poético. Santiago de Chile: Ed. Nómade.

Labraña, Marcela. 1999. "La Nueva Novela de Juan Luis Martínez". Vértebra: Santiago de Chile, 52-5.

Lastra, Pedro y Lihn, Enrique. 2001. "Señales de ruta de Juan Luis Martínez". Merodeos en torno a la obra de Juan Luis Martínez. Intemperie ediciones: Santiago de Chile. 39-44.

Lauer, Mirko. 1990 [1983]. I-Ching. Madrid: Ediciones Akal.

Martínez, Juan Luis. 2012. El poeta anónimo (o el eterno presente de Juan Luis Martínez). Brasil: Cosac Naify.

1985 [1977]. La nueva novela. Santiago de Chile: Ediciones Archivo. 2003. Poemas del otro. Santiago de Chile: Universidad Diego Portales.

2010. Aproximación de un Principio de Incertidumbre a un proyecto poético. Santiago de Chile: Ed. Nómade.

Todorov, Tzvetan y Ducrot, Oswald. 2003. Diccionario enciclopédico de las ciencias del lenguaje. Buenos Aires: Siglo Veintiuno Editores. 
Weintraub, Scott. 2010. "Juan Luis Martínez y las otredades de la metafísica. Apuntes patafísicos y carrollianos". Estudios 18, 35: 141-168. En línea; disponible en http://www. revistaestudios.com.ve/wp-content/uploads/2012/02/S-Wientraub.pdf (4/02/2013).

Wikipedia. "Hipercubo". En línea; disponible en: http://es.wikipedia.org/wiki/Hipercubo (10/06/2012).

"I- Ching". En línea; disponible en: http://es.wikipedia.org/wiki/I Ching $(10 / 06 / 12)$. 
